\title{
Concussion History, Mental Health, and Attention-Related Errors among Female Amateur MMA Fighters at the 2019 IMMAF European Championship: A Descriptive Study
}

\author{
${ }^{1}$ Ingunn Unnsteinsdottir Kristensen ${ }^{(\mathbb{D} *}{ }^{2}$ Hafrún Kristjánsdóttir ${ }^{(D)}{ }^{3}$ María K. \\ Jónsdóttir \\ ${ }^{1}$ Department of Psychology, School of Social Sciences, Reykjavik University, Reykjavik, \\ Iceland. ${ }^{2}$ Landspitali-The National University Hospital of Iceland, Iceland. ${ }^{3}$ Physical Activity, Physical \\ Education, Sport and Health (PAPESH) Research Centre, Sports Science Department, School of Social \\ Sciences, Reykjavik University, Reykjavik, Iceland.
}

Submitted 26 November 2020; Accepted in final form 12 January 2021.

\begin{abstract}
Background. Increasingly, women are training and competing in mixed martial arts (MMA). Women are, however, hugely underrepresented in the research literature. Objectives. The purpose of this brief report was to assess concussion knowledge, mental health and attention-related errors among female MMA competitors and factors that might affect data quality when doing a study during a competition. Methods. Forty-one athletes participated at

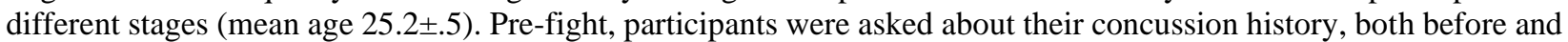
after being given a definition. They answered questions about MMA background and completed the Patient Health Questionnaire-9, the General Anxiety Disorder Questionnaire-7, the Depression, Anxiety, and Stress Scale-21, the Sports Concussion Assessment Tool-5 (also completed post-fight), and the Sustained Attention Response Task. Two weeks later, competitors were asked to answer mental health questionnaires and the concussion symptom scale again. Results. Mean years in MMA were 7.3 \pm 5.5 . Before reading a concussion definition, $16.7 \%$ reported a concussion history, $30.6 \%$ reported a concussion history after reading the definition. The error score on the attention response task was 12.12 \pm 6.55 . Pre-fight, the SCAT5 score was 9.0 \pm 8.6 , post-fight it was $9.1 \pm 6.8$, and two weeks later, 7.3 \pm 11.2 . Scores on mental health scales were between 3.9-5.9 $\pm 3.7-4.6$ pre-fight and between 4.3-6.1 $\pm 5.9-10$ two weeks later. Conclusion. The change in concussion reporting indicates a lack of knowledge; scores on symptoms scales and attention test did not indicate problems. Factors affecting side-line evaluation included coaches' willingness to participate and the athletes' emotional state. Significant limitations of this study included possible language barriers. Therefore, results should be interpreted with caution.
\end{abstract}

KEYWORDS: Sport-Related Concussion, Head Trauma, Female, MMA.

\section{INTRODUCTION}

There is a need for more studies on mixed martial arts (MMA). Few studies are done ringside, and even fewer have women as participants even though, globally, more and more women are training and competing in MMA
(1). An article published in 2019 (1), exploring the Nordic female fighter concluded that women have less experience in other combat sports than men and are less motivated to compete than men. Rather, women's main reasons for training MMA

*. Corresponding Author:

Ingunn Unnsteinsdottir Kristensen, Ph.D.

E-mail: ingunnu@ru.is 
were better health, enjoyment, improved selfconfidence and body awareness.

Female MMA fighters are hugely underrepresented in the MMA literature (2), which is a concern. Thus, it is unclear if results and practical application derived from existing studies apply to female fighters as well as males. This is important as women may be at a greater risk of sustaining head trauma, such as concussion, than men and suffering worse consequences (3). Head trauma is common when practising and training MMA (4). The neck, head, and upper body are the most commonly injured body parts, and different types of fight outcomes are a risk factor (e.g., knock out, no contest, submission) $(2,5,6)$. A concussion is defined as a blow to the head or elsewhere to the body, transmitted to the head, causing symptoms indicating neurological dysfunction such as headache, memory loss, irritability or balance problems (7). Symptoms can vary and are usually short-lived. In some cases, however, they can become more persistent (7). Long term consequences of traumatic brain injury in modern-day combat sports may include persistent post-concussion symptoms, dementia, parkinsonism, and persistent headaches $(8,9)$. Worse mental health has been connected to sportrelated concussion history (10). However, this has not been studied among MMA fighters.

This study aimed to examine self-reported concussion history and factors that can be affected by concussion history among amateur female MMA fighters at the 2019 IMMAF European championship. This included pre-fight attentionrelated errors, mental health and factors that might affect data quality when doing a study during a competition. Concussion symptoms were also assessed post-fight and concussion symptoms and mental health two weeks post-competition.

\section{MATERIALS AND METHODS}

Participants. All female fighters that competed at the Europeans $(\mathrm{N}=58)$ were invited to participate in the study. Forty-one athletes (12 nationalities; $71 \%$ participation rate) participated at different stages (Age $=25.2 \pm 5.5)$.

Measures. Mental health was assessed with the Patient Health Questionnaire (PHQ-9) (11), the General Anxiety Disorder Questionnaire (GAD-7) (12), and the Depression, Anxiety, and
Stress Scale (DASS-21) (13). All scales have good psychometric properties and have been used in athletic populations and with groups at risk for concussion (10). The Sustained Attention to Response Task (SART) was used to assess attention-related errors (14). The Sports Concussion Assessment Tool 5 (SCAT5) was used to assess post-concussive symptoms (7). Information about which fights ended with a knockout (KO) or a technical knockout (TKO) was collected during the competition. A KO is when a fighter is knocked down and cannot resume fighting; a TKO is when a referee declares a fighter unable to continue.

Procedure. The study took place at the 2019 IMMAF European championship, in partnership with the IMMAF medical team. Before arriving, all female athletes expected to compete were sent an e-mail informing them about the study and were invited to participate.

Before competing, 36 (88\%) completed mental health questionnaires and the SART. After their last fight, following the post-fight medical check-up, 32 of the $36(89 \%)$ answered the concussion symptom scale again. Two weeks later, all the athletes who participated at the Europeans $(\mathrm{N}=58)$ received an e-mail with a link to the mental health questionnaires which $24 \%$ $(\mathrm{n}=14)$ completed.

Pre-fight, participants were asked if they had sustained a concussion before and after being given a definition (15). The definition was based on the 2016 Consensus statement on concussion in sports (7). Participants also answered questions about their background in combat sports and completed the PHQ-9, the GAD-7, the DASS-21, the SCAT5, and the SART. Following their last fight, the SCAT5 was administered again as soon as participants had finished their post-fight medical check-up. Two weeks later, competitors were asked to complete the PHQ-9, the GAD-7, the DASS-21, and the SCAT5 again. The participants signed a consent form.

Data Analysis. Descriptive statistics, means and standard deviations, were calculated for the SCAT5 severity score, total scores on the DASS21, the PHQ-9, DASS21, GAD-7, and the SART error score (SARTes). Concussion history and demographic characteristics were summarized using counts and percentages. SPSS, version 26, was used for data analysis. 


\section{RESULTS}

Background in combat sports can be seen in Table 1. A total of 23 , or $26 \%$, of female fights at the Europeans, ended with a KO or a TKO.

Before being given a concussion definition, $16.7 \%(\mathrm{n}=6)$ reported a concussion history, $72.2 \%$ (26) reported no concussion, and $11.1 \%$ $(n=4)$ did not know if they had sustained one. After being given a definition, these numbers changed to $30.6 \%(n=11), 61.1 \%(n=22)$, and $8.3 \%(\mathrm{n}=3)$, respectively. Pre-fight the symptom

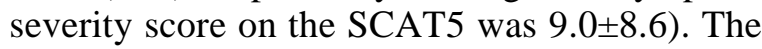
SARTes was $12.12 \pm 6.55)$. The symptom

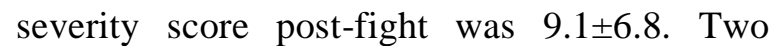
weeks later, the symptom severity score was 7.3 \pm 11.2 .

Scores on mental health scales, both pre-fight and two weeks after the competition, can be seen in Table 2. All scores on the GAD-7 and the PHQ9, both pre-competition and two weeks later could be categorized as mild $(11,12)$. Scores on the DASS, depression and anxiety scales, both precompetition and two weeks later is categorized as mild (13). Scores on the DASS stress scale, both pre-competition and two weeks later is considered normal (13).

Table 1. Background in Combat Sports (Asked before the Competition)

\begin{tabular}{|ccc}
\hline & Mean & Std. \\
\hline Years training combat sports (MMA, Kickbox, and Box) & 7.3 & 5.5 \\
MMA & 3.35 & 2.01 \\
Kickbox & 2.43 & 3.85 \\
Box & 1.53 & 3.52 \\
\hline Number of fights (MMA, Kickbox, and Box) & 12.36 & 22.12 \\
\hline MMA & 4.39 & 3.32 \\
Kickbox & 5.31 & 16.80 \\
Box & 2.67 & 15.66 \\
Fights lost because of KO/TKO* (MMA, Kickbox, and Box) & 0.39 & 0.69 \\
MMA & 0.36 & 0.64 \\
Kickbox & 0.03 & 0.16 \\
\hline Box & 0 & 0 \\
\hline
\end{tabular}

*knockout/ technical knockout.

Table 2. Mean Scores on Mental Health Scales

\begin{tabular}{lcccccc}
\hline Mental Health & \multicolumn{3}{c}{ Before the Competition } & \multicolumn{2}{c}{ Two Weeks after the Competition } \\
\hline & $\mathrm{N}$ & Mean & Std. & $\mathrm{N}$ & Mean & Std. \\
GAD & 33 & 3.9 & 3.7 & 13 & 4.8 & 6.3 \\
PHQ & 35 & 3.8 & 3.6 & 13 & 6.1 & 5.9 \\
DASS depression & 32 & 5.9 & 4.5 & 12 & 5.3 & 7.6 \\
DASS anxiety & 31 & 5.8 & 4.5 & 12 & 6.0 & 10.0 \\
DASS stress & 34 & 3.9 & 4.3 & 13 & 4.3 & 7.4 \\
\hline
\end{tabular}

\section{DISCUSSION}

This study provides a short description of factors relating to concussion history and measures indicative of mental health among amateur female competitors in MMA. Very little has been reported on female fighters in MMA in general and this report offers preliminary insight. As in previous studies of other sports, an increase in concussion estimate before and after being given a definition indicated lack of knowledge $(15,16)$. Approximately one-third of the participants $(30.6 \%)$ reported having had a concussion before the competition. Not much is known about concussion prevalence among MMA fighters. KO/TKO prevalence could be between $28.3 \%-46.2 \%$ depending on the weight class, but little is known about the severity and possible long-term effects of concussion in MMA (5). The mean SART error score was $12.12 \pm$ 6.55), which does not indicate a problem (17). Scores on depression and anxiety scales, both prefight and two weeks post-competition, showed no to mild symptoms of depression, anxiety, and stress (11-13).

When doing a study during a competition, it is important to consider factors not present in a more controlled environment that might affect data quality. There is a need for ringside studies in MMA, as few studies exist (2). Participants in this study were focused on the upcoming competition and did not want distractions. It was, therefore, essential to have coaches engaged in the process. Their involvement meant a willing participant. 
Getting the coaches involved was, for the most part, not difficult. However, during the follow-up two weeks later, it was not easy to get a reply from participants when coaches were not involved. The post-fight evaluation was done immediately after a medical check-up. This meant most had just dropped out of the competition; many were emotional and wanted to get through the questions quickly. A follow-up couple of hours later or a day later would have been more feasible. A later follow-up should be presented as a further medical check-up, beneficial for the athlete.

A significant limitation of this study was the language barrier. The GAD, the DASS and the PHQ were presented in 12 languages before the competition. However, everything else and all instructions were in English. All participants claimed that they understood English, but limitations were apparent when talking to some of them, and the researcher could not be sure if everything was always understood as intended. The follow-up included only versions in English. Another limitation was that it was impossible to compare data from before the competition and two weeks later. This was because all participants were invited to participate. Due to this, some of the athletes who did not participate before the competition did participate two weeks later. Because of these limitations and the small sample results should be interpreted with caution.

\section{CONCLUSION}

Although scores on concussion symptoms scales and the attention test did not indicate a problem, the change in the self-reported number of concussions following a definition indicates a lack of concussion knowledge. Factors affecting side-line evaluation included coaches' willingness to participate, and the athletes' emotional state should be considered when gathering data during a competition. This study's results and consideration from the author give important insight into factors connected to concussion among MMA female fighters and limitations when doing a study during an international competition. In this study, participants were of 12 different nationalities. MMA championships involve participants from many countries, and not all may be fluent in English. This poses particular methodological challenges. Given the nature of the sport, we call for international collaboration in studying concussion among MMA fighters, females, and males.

\section{APPLICABLE REMARKS}

- The present findings indicate a lack of concussion knowledge among female MMA fighters competing in MMA.

- This is a concern as this group is at risk for head trauma.

- Coaches and organizations should consider implementing appropriate measures to make sure athletes have the appropriate information regarding concussion and head trauma.

- Present findings also include important information researchers should consider when doing a study during a competition.

- Researchers should get the coaches involved; a successful pre- and post-competition evaluation could depend on their involvement as well as on an international team of researchers with a varied linguistic background.

\section{ACKNOWLEDGMENTS}

To the MMA athletes that participated, coaches, and the IMMAF team, especially the medical team.

\section{DECLARATION OF INTEREST \\ None.}

\section{ETHICAL CONSIDERATION}

This study was approved by the Reykjavik University Ethics Committee.

\section{FUNDING}

This study was supported in part by $\mathrm{Ph} . \mathrm{D}$. grant nr. 195683-052 from the Icelandic Centre for Research (Rannís).

\section{REFRENCES}

1. Alsarve D, Tjønndal A. 'The Nordic female fighter': Exploring women's participation in mixed martial arts in Norway and Sweden: Int Rev Sociol Sport [Internet]. 2019. Available from: https://journals.sagepub.com/doi/10.1177/1012690218822307.

2. Thomas RE, Thomas BC. Systematic review of injuries in mixed martial arts. Phys Sportsmed. 2018;46(2):155-167. doi: 10.1080/00913847.2018.1430451 pmid: 29347856

3. McGroarty NK, Brown SM, Mulcahey MK. Sport-Related Concussion in Female Athletes: A Systematic Review. Orthop J Sports Med. 2020;8(7):2325967120932306. doi: 10.1177/2325967120932306 pmid: 32728590 
4. Heath CJ, Callahan JL. Self-reported concussion symptoms and training routines in mixed martial arts athletes. Res Sports Med. 2013;21(3):195-203. doi: 10.1080/15438627.2013.792082 pmid: 23777375

5. Follmer B, Dellagrana RA, Zehr EP. Head Trauma Exposure in Mixed Martial Arts Varies According to Sex and Weight Class. Sports Health. 2019;11(3):280-285. doi: 10.1177/1941738119827966 pmid: 30768376

6. Miarka B, Coswig V, Brito JC, Slimani M, Amtmann J, Vecchio FBD. Comparison of combat outcomes: technical and tactical analysis of female MMA. Int J Perform Anal Sport. 2016;16(2):539-552. doi: 10.1080/24748668.2016.11868907

7. McCrory P, Meeuwisse W, Dvorak J, Aubry M, Bailes J, Broglio S. Consensus statement on concussion in sport-the 5th international conference on concussion in sport held in Berlin, October 2016. Br J Sports Med. 2017;51(11):838-847.

8. Koerte IK, Lin AP, Willems A, Muehlmann M, Hufschmidt J, Coleman MJ, et al. A review of neuroimaging findings in repetitive brain trauma. Brain Pathol. 2015;25(3):318-349. doi: 10.1111/bpa.12249 pmid: 25904047

9. Seifert T. Neurologic Health in Combat Sports. Neurol Clin. 2017;35(3):523-535. doi: 10.1016/j.ncl.2017.04.001 pmid: 28673413

10.Jónsdóttir MK, Kristófersdóttir KH, Runólfsdóttir S, Kristensen ISU, Sigurjonsdottir HA, Eggertsdottir Claessen. Concussion among female athletes in Iceland: Stress, depression, anxiety and quality of life. Press.Press.

11. Kroenke K, Spitzer RL, Williams JB. The PHQ-9: validity of a brief depression severity measure. J Gen Intern Med. 2001;16(9):606-613. doi: 10.1046/j.1525-1497.2001.016009606.x pmid: 11556941

12.Spitzer RL, Kroenke K, Williams JB, Lowe B. A brief measure for assessing generalized anxiety disorder: the GAD-7. Arch Intern Med. 2006;166(10):1092-1097. doi: 10.1001/archinte.166.10.1092 pmid: 16717171

13.Lovibond SH, Lovibond PF. Manual for the Depression Anxiety \& Stress Scales. Sidney Psychol Found. 1995;2. doi: 10.1037/t39835-000

14. Robertson IH, Manly T, Andrade J, Baddeley BT, Yiend J. 'Oops!': Performance correlates of everyday attentional failures in traumatic brain injured and normal subjects. Neuropsychol. 1997;35(6):747-758. doi: 10.1016/S0028-3932(97)00015-8

15. Kristjansdottir H, Brynjarsdottir RM, Kristensen ISU, Sigurjonsdottir HA, Claessen LOE, Jonsdottir MK. Self-reported concussion history among Icelandic female athletes with and without a definition of concussion. Clin Neuropsychol. 2020;34(sup1):70-82. doi: 10.1080/13854046.2020.1814873 pmid: 32990154

16. Robbins CA, Daneshvar DH, Picano JD, Gavett BE, Baugh CM, Riley DO, et al. Self-reported concussion history: impact of providing a definition of concussion. Open Access J Sports Med. 2014;5:99-103. doi: 10.2147/OAJSM.S58005 pmid: 24891816

17. Carriere JS, Cheyne JA, Solman GJ, Smilek D. Age trends for failures of sustained attention. Psychol Aging. 2010;25(3):569-574. doi: 10.1037/a0019363 pmid: 20677878 